\title{
A pedagogia da alternância e o ensino de história: o caso da escola família agrícola de Santa Cruz do Sul
}

\author{
Pedagogy of Rotating and history of education: \\ Family School case Agricultural of Santa Cruz do Sul \\ Mariana Barbosa de Souza \\ João Paulo Reis Costa \\ Cristina Luisa Bencke Vergütz
}

Universidade de Santa Cruz do Sul - Unisc - Santa Cruz do Sul - Rio Grande do Sul - Brasil

Resumo: Analisa o ensino da história a partir da Pedagogia da Alternância na Escola Família Agrícola de Santa Cruz do Sul (EFASC), localizada no Vale do Rio Pardo, região central do Rio Grande do Sul. O sustentáculo teórico do texto são os ensinamentos de Paulo Freire e, a partir deste ensinamento exsurge o pensamento de que os saberes não podem ser postos em uma hierarquia de importância. Percebe-se que os quatro pilares de uma EFA (Associação Local, Pedagogia da Alternância, Formação Integral e Desenvolvimento do Meio), juntamente com todos os seus vários instrumentos pedagógicos podem contribuir para o desenvolvimento regional, através da formação de jovens (filhos/as de Agricultores Familiares) como técnicos agrícolas, formados no processo de ensino-aprendizagem da Pedagogia da Alternância, com ampla participação das famílias e suas comunidades. A abordagem é qualitativa através da análise e interpretação do referencial teórico, dos dados obtidos com a pesquisa documental relacionada com a experiência empírica da atuação junto à Escola Família Agrícola de Santa Cruz do Sul - EFASC. São objetivos específicos: contextualizar historicamente a Pedagogia da Alternância nas diversas escalas (mundial, nacional e local); e compreender o ensino da história na EFASC fundamentado na Pedagogia da Alternância, a qual se apresenta alinhavada por instrumentos pedagógicos, dentre os quais foram destacados: O Plano de Formação, o Plano de Estudo e a Colocação em Comum, contrapondo nesse caso, uma perspectiva de Educação bancária e descontextualizada da realidade dos sujeitos envolvidos.

Palavras-chave: Pedagogia da Alternância. História. Educação do Campo.

Abstract: Analyzes the teaching of history from the Pedagogy of Alternation the School Agricultural Family, Santa Cruz do Sul (EFASC), located in the Rio Pardo Central Valley of Rio Grande do Sul. This text are the teachings of Paulo Freire and, from this teaching Exsurge thought that knowledge can not be put into a hierarchy of importance. It is noticed that the four pillars of EFA (Local Association, Pedagogy of Alternation, and Integral Development of the training), along with all its various educational tools can contribute to regional development through the training of young people (children / the Farmers family) as agricultural technicians trained in the teaching-learning Pedagogy of Alternation, with broad participation of families and their communities. The approach is qualitative through the analysis and interpretation of the theoretical framework, the data obtained with the documentary research on the empirical experience of the performance by the School Agricultural Family of Santa Cruz do Sul - EFASC. Specific objectives: to contextualize historically the Pedagogy of Alternation in the different scales (global, national and local); and understand the teaching of history in the reasoned EFASC in Pedagogy of Alternation, which presents basted by pedagogical tools, among which were highlighted: The Training Plan, the Study Plan and Commissioning Common, contrasting this case, a perspective bank Education and out of context reality of the subjects.

Keywords: Pedagogy of Alternation; History; Rural Education. 


\section{Introdução}

Este artigo objetiva abordar, de forma breve, o ensino da História na Escola Família Agrícola de Santa Cruz do Sul - EFASC, tendo como pano de fundo a Pedagogia da Alternância, levando em consideração as concepções adotadas pelo sistema educacional brasileiro, bem como o fato de a escola ser compreendida como um espaço de resistência para acesso à cultura, convivência social, ofertando uma formação crítica e cidadã aos seus sujeitos, numa perspectiva da Educação do Campo, comprometida com a Agroecologia e com a Agricultura Familiar, na região do Vale do Rio Pardo/RS.

A Pedagogia da Alternância possibilita ao educando, estudar na escola durante um período (uma semana, no caso da EFASC), na sessão escolar, contextualizada com a sua realidade, partilhando-a com seus pares e se apropriando de novos saberes para no outro período, na sessão familiar, colocá-los em prática na propriedade em que reside com sua família. Desta forma, a Pedagogia da Alternância possibilita um vínculo direto do jovem com a escola, com a família, bem como com a comunidade em que vive, articulando esses espaços e tempos, desenvolvendo os vários instrumentos pedagógicos, aos quais os estudantes vão se apropriando durante a formação.

Nesse contexto, a escola detém fundamental importância, não sendo possível a sua generalização, porquanto cada escola possui uma carga história única, que a torna ímpar e com características exclusivas, de acordo com a realidade em que ela está contextualizada. Associada à escola, tem-se a diversidade cultural, a qual não pode ser ignorada visto que a sociedade é complexa e sofre constantes transformações.

Ademais, o artigo está divido, além desta introdução, em seções que tratam os temas relativos à contextualização histórica da Pedagogia da Alternância e ao ensino da História a partir desta, reafirmando que "estudar é uma forma de reinventar, de recriar, de reescrever - tarefa de sujeito e não de objeto" (FREIRE, 1978, p. 10).

\section{Aspectos históricos da Pedagogia da Alternância}

A Europa, em meados do século $X X$, organizava a sociedade industrial moderna, por meio diacronia cidade/meio urbano, enquanto espaço central frente ao modelo econômico. Por outro lado, o campo se configurava como um apêndice desse modelo, reproduzindo essa lógica mercantil. Discussão essa, que passaria pela escola, que até meados do século $X X$ apenas reproduz o ensino urbano numa Europa industrial. Mais precisamente, pela França, entrecortada por duas grandes guerras mundiais e uma devastadora crise econômica, a de 1929, até então sem precedentes.

Esse período é determinante na medida em que os agricultores foram deveras importantes para a alimentação dos soldados, bem como das populações que lutavam contra a escassez alimentar, mesmo diante de um Europa encantada com a industrialização, responsável por consolidar o capital internacional.

É neste contexto que surge uma chance concreta de alterar o paradigma da educação dos povos do campo, os quais necessitavam de acesso ao conhecimento a partir do espaço no qual encontravam-se inseridos, em outras palavras, necessitavam alçar o conhecimento a partir da sua vivência, contrariamente à educação tradicional da cidade, descontextualizada da vida dos agricultores. A necessidade de um novo modelo educacional atravessa a França, a Itália, a Espanha e outros países europeus e no século $X X$ chega, também, a outros continentes. Uma tentativa de educação direcionada às necessidades dos agricultores, que iniciaria do conhecimento presente nas comunidades e complementaria a ciência acadêmica, sem a necessidade de os jovens viverem na cidade para estudar.

Assim, a proposta reunia estudos com afazeres domésticos. É nesse período, marcado por 
um Europa urbana e industrial que via no campo um lugar de atraso e, portanto, o tratava com desprezo, que se cria um novo modelo de educação, voltado às populações camponesas, mais especificamente a partir de 1930 na França. Nesse caso, após a recusa de quatros adolescentes franceses, de frequentar a escola da Vila, estaria iniciando um novo jeito de fazer escola. Conforme aponta o diálogo entre os pais de um desses meninos com o padre da comunidade, demostrando parte da realidade do campo francês na década de 1930:

Um agricultor e o padre conversavam uma tarde de junho de 1935. Pelas testas enrugadas e pelo tom geral as vozes, podia perceber-se que uma preocupação profunda dominava a conversa. De fato, a conversa estava centrada sobre o futuro de um belo adolescente que havia ingressado há um ano no certificado de estudos. - Ele tem nojo da escola superior, dizia seu pai. Cada vez que ele deve ir à escola aparecem novas lamentações. Entretanto parar de estudar aos 13 anos é lamentável!... - Sim, é sempre isso: o agricultor, não vale grande coisa na sociedade francesa, respondeu o padre. Para as crianças, a escola primária é até os 13 anos. - E daí o que vale esta escola? Nós temos excelentes professores - quando não se metem a fazer política - mas programas detestáveis!... Mesmo o certificado de estudos não significa mais nada.... Um ano depois, aqueles que obtiveram, não sabem nada mais que os outros! - E depois, colocar nossos filhos num pensionato custa caro! Pouco dinheiro não resolve não! $\mathrm{E}$ para chegar a que? Ver nossos filhos nos olharem do alto quando eles retornam após três meses de pensionato na cidade. A terra, eles começam rápido a achar que ela está muito baixa, estes jovens agricultores transformados em urbanos "sábios"... - Sábios! Se pelo menos ficassem sábios. Mas lá também, os programas não são feitos para a agricultura! Aliás, as turmas são grandes de mais; o professor dá seu curso, compreenda quem puder. Ele não pode se ocupar de cada um em particular. - E as escolas de agricultura? Ah! Sim.... Quantos verdadeiros agricultores o senhor já viu sair de uma escola de agricultura? - Não, realmente, nada é feito oficialmente para garantir a formação intelectual de jovens agricultores em uma época onde, mais do que nunca, os agricultores precisam ser verdadeiros sábios; numa época em que a agricultura precisa de chefes que sejam verdadeiros líderes. A conversa continua cada vez mais pessimista quando, de repente, como um relâmpago, surge uma nova idéia: Diante dessa deficiência, porque não criar alguma coisa nova que se adapte realmente ao meio agrícola? Um tipo de escola que nós possamos criar aqui mesmo? Desta vez, a conversa passou a ser mais otimista animadora, reconfortante. Quando o agricultor se despede do padre, com alegria no seu olhar, um projeto de formação intelectualprofissional dos jovens agricultores, dos futuros líderes agricultores, já estava elaborado em grandes linhas (TANTON, 1999, p. 98-99).

O diálogo entre o padre o agricultor, na França de 1930, traduzir-se-á na tentativa de sanear o anseio por um conhecimento diverso do que era apresentado pela escola formal, imutável frente às necessidades dos seus educandos, bem como das comunidades nas quais encontravam-se inseridas. Assim, surge o movimento da alternância em 1935.

Nascido das necessidades e preocupações com relação ao acesso à educação das populações do campo, da falta de uma educação de acordo com as suas realidades, exonerando-se de gastos que impediam o acesso dos filhos dos agricultores mais pobres à educação, até então hospedados em pensionatos nas cidades, nasce a Pedagogia da Alternância. Com o avanço da cidade sobre o campo, intensificado na Europa pós-primeira guerra mundial e, posteriormente, com a segunda grande guerra, a fim de atender os anseios das atividades urbanas, industriais sobretudo, houve, também a intensificação do êxodo rural na maior parte dos países europeus.

Nesse contexto é dado o pontapé inicial para a posterior consolidação da Pedagogia da Alternância:

O movimento das Casas Familiares Rurais nasceu em 1935, a partir da iniciativa de três agricultores e um padre de um vilarejo da França (Lauzun) (...) prestaram atenção em um adolescente de 14 anos que rejeitava escola em que estava matriculado (...). Então, fora das estruturas escolares estabelecidas e sem referência a qualquer teoria pedagógica, eles imaginaram um conceito de formação que permitiria seus filhos educar-se, formarem-se e prepararem-se para suas futuras profissões (...) Eles criaram empiricamente uma estrutura de formação que seria de responsabilidade dos pais e das forças sociais locais (...) Eles inventaram uma fórmula de escola baseada na Pedagogia da Alternância que induz uma partilha do poder educativo entre os atores do meio, pais e os formadores da escola. Em 1935, eram quatro jovens, (...) no ano seguinte dezesseis jovens, (...) dois anos mais tarde eram quarenta estudantes. Os agricultores, pais desses jovens agruparam-se numa associação, fizeram um empréstimo bancário e usaram o 
próprio financiamento para comparem uma casa (...) a Casa Familiar de Lauzun e contrataram um formador. Assim foi criada a primeira Casa Familiar em 1937. (...) Só em 1960 uma lei reconheceu como modalidade pedagógica com a Alternância (...) uma segunda lei em 1984 reforçou esse reconhecimento e a ajuda do estado (GIMONET, 1999, p. 40-41).

O diferencial, que faz com que essa escola se distinga de todas as tentativas de educação para populações do campo, é a tentativa de aliar a prática agropecuária com a teoria científica. Essa forma de fazer escola chegaria em pouco tempo a diferentes países europeus e mais tarde no mundo, especialmente o Brasil e Argentina a partir de meados de 1960

A Pedagogia da Alternância se organiza com o estudante permanecendo um período em casa e outro na EFA, alternando momentos de sua formação. Nesse caso, a família/comunidade e a escola rompem com a ideia não construtiva, que ainda insiste em permanecer no dia-a-dia, e trata a escola como sendo a fonte única, ou a principal responsável pela educação das pessoas. Esse ideal desconsidera a família, a comunidade, bem como as relações socioculturais estabelecidas no meio no qual os educandos encontram-se inseridos (COSTA, 2012).

A Pedagogia da Alternância, como uma metodologia para organizar a educação do campo, tem raízes nas lutas dos agricultores familiares franceses da década de 1930. Os jovens que ficavam no campo, geralmente não tinham acesso à formação escolar em níveis mais elevados, a tendência (...) era estudar nas escolas do meio urbano, sendo que a maioria dos que saiam para estudar na cidade não voltavam para o campo (...) por isso a iniciativa de uma escola diferenciada podia reverter o processo e não precisar sair do campo para estudar e nem estudar para sair do campo. Escola camponesa foi a primeira denominação dada pelos agricultores antes de passar a ser chamada de Casa Familiar ou Escola Família (BEGNAMI, 2004, p. 4).

Essa concepção de escola, de educação adquire respaldo em diferentes países e atende diferentes públicos, não somente agricultores familiares, visto que o Campo não é lugar exclusivo dos agricultores, pois outros trabalhadores que residem nesse espaço também trabalham e ganham sua vida, tem a oportunidade de acessar essa vivência educativa-pedagógica. Chama-se atenção para uma concepção educacional que envolve um conceito de ruralidade, necessário num Estado como o Rio Grande do Sul, que possui diversos municípios considerados rurais.

Nesse viés de uma educação preocupada com o meio, a partir de uma visão que considera os jovens e o meio no qual estão inseridos, a Pedagogia da Alternância alcança espaço em outros países, sendo considerada uma referência metodológica preocupada com o meio e com a formação integral dos educandos. Assim, tem-se o crescimento dos seus Centros Educativos Familiares de Formação em Alternância - CEFFAS em todo o mundo. $\mathrm{Na}$ designação CEFFA reúnem instituições que trabalham com a Pedagogia da Alternância, no caso brasileiro são: as EFA's - Escolas Família Agrícola, as CFR's - Casas Familiares Rurais, ECOR's - Escolas Comunitárias Rurais, que se fundamentam na Pedagogia da Alternância e respeitam os quatro pilares de um CEFFA: Associação Local, Alternância, Formação Integral e Desenvolvimento do Meio (COSTA, 2012). Embora nesse trabalho se destacará apenas a Pedagogia da Alternância vinculada e vivenciada pelas EFAs.

Com o avanço da Pedagogia da Alternância por meio dos CEFFAS em todo o mundo, é criada em Dakar, entre os dias 12 e 16 de maio de 1975, uma entidade internacional responsável por reunir os sujeitos desse movimento:

A AIMFR (Associação Internacional dos Movimentos Familiares de Formação Rural) representa as diferentes Instituições promotoras de Escolas de Formação por Alternância para jovens do meio rural. Ditas Escolas (mais de 1300 distribuídas por mais de 40 países da África, América, Ásia, Europa e Oceania) envolvem em processo de desenvolvimento local a mais 150 mil famílias rurais. (...) A AIMFR tem como objetivo fomentar e promover o desenvolvimento dos CEFFA no mundo. Representar os interesses dos CEFFA ante os organismos supranacionais e internacionais e estabelecer relações com eles. Difundir ante a opinião pública - especialmente nos âmbitos rural, 
profissional e familiar - os princípios dos CEFFA definidos em seus estatutos e velar por sua correta aplicação (...). (MARIRRODRIGA e CALVÓ, 2010, p. 47-51).

O movimento da Pedagogia da Alternância iniciado na França em 1935, chega ao Brasil pouco mais de 30 anos após, a fim de se tornar uma importante contribuição pedagógica ao meio rural do Brasil nos séculos XX e XXI. Vai ser no estado do Espírito Santo que o movimento da Pedagogia da Alternância encontra sua primeira manifestação brasileira. Durante a ditadura militar, em 1965, o jovem sacerdote católico Padre Humberto Pietrogrande, italiano, articulou a igreja com os agricultores e entidades locais, transformando esta experiência em um ato inédito na educação do campo brasileira, e na América do Sul (COSTA, 2012).

É somente após os anos de 1970 que as EFAs conquistam outros espaços pelo Brasil: Bahia, Minas Gerais, Maranhão, Amapá e demais estados. Esse processo expansivo se deu com forte auxílio da Igreja Católica, sobretudo pelo movimento das CEBs (Comunidades Eclesiais de Base), que sempre teve muita força junto aos agricultores familiares pelo interior do Brasil. Com isso recebe forte apoio popular ante o envolvimento dos agricultores e demais sujeitos que vivem no meio, articulado em diversas entidades e com o próprio poder público. Desde então, o movimento das EFAs visa a parceria com o poder público, com a criação de aparatos jurídicos, como a criação de leis municipais, estaduais e federais que respaldem o repasse de verbas públicas para as EFA's.

As EFAs foram ocupando espaço no Brasil e ampliando sua atuação no território nacional. Primeiro com as regionais, como o MEPES (Movimento de Educação Promocional do Espírito Santo) fundado em 1968. Depois com a fundação, em 1979, da AECOFABA (Associação das Escolas das Comunidades e Famílias Agrícolas da Bahia). Essas entidades já proporcionavam uma base interessante para a criação da UNEFAB (União Nacional das Escolas Famílias Agrícolas do Brasil) fundada em 1982, com a finalidade de ser uma instituição de representação e assessoria às associações e EFAs no Brasil, auxiliando no fortalecimento, fomento e divulgação da Pedagogia da Alternância. A sede da UNEFAB se localiza em Orizona/GO (COSTA, 2012).

Segundo COSTA (2012), no Rio Grande do Sul o movimento CEFFA repete lógica nacional, possuindo a presença de duas instituições nacionais representadas pelas CFRs (Casas Familiares Rurais) e pelas Escolas Família Agrícola (EFA), que inicia sua caminhada em 2008, com a fundação da AGEFA (Associação Gaúcha Pró- Escolas Famílias Agrícolas), sendo essa associação local que mantém a EFASC (Escola Família Agrícola de Santa Cruz do Sul), fundada em 1\%3/2009, com sede em Santa Cruz do Sul, região central do estado. Estando dessa forma a Escola Família Agrícola de Santa Cruz do Sul ligada a um movimento estadual (AGEFA), nacional (UNEFAB) e internacional (AIMFR) (COSTA, 2012).

A associação local da EFASC nesse caso a AGEFA, mantém a escola com recursos advindos de várias fontes, fruto de uma articulação regional. Além das famílias contribuem espontaneamente, há convênios via projeto de lei com 8 municípios da região do VRP (Santa Cruz do Sul, Venâncio Aires, Passo do Sobrado, Vale Verde, Vera Cruz, Sinimbu, Herveiras e Gramado Xavier), além de acesso ao FUNDEB desde 2014 e convênio via projeto com a SDR (Secretaria de Desenvolvimento Rural, Pesca e Cooperativismo), desde 2014. Ademais, a EFASC conta também com o apoio de entidades regionais, como a UNISC (Universidade de Santa Cruz do Sul), SICREDI - VRP, AFUBRA (Associação dos Fumicultores do Brasil), SINDITABACO (Sindicato da Indústria do Tabaco), $6^{\mathrm{a}} \mathrm{CRE}$, Mitra Diocesana, FETAG/RS - Federação dos Trabalhadores da Agricultura, CDI (Comitê para Democratização da Informática), Pioneer Sementes, PMB (Phillip Morris do Brasil), JTI (Japan Tobacco International). Também há outros parceiros pontuais em projetos e trabalhos de campo, como a UFRGS (Universidade Federal do Rio Grande do Sul), UERGS (Universidade Estadual do Rio Grande do Sul), UFSM (Universidade Federal de Santa Maria), MPA (Movimento dos Pequenos Agricultores), CAPA 
(Centro de Apoio e Promoção da Agroecologia), EMATER/RS, EMBRAPA Clima Temperado.

A demanda por experiências como as EFA's no estado corrobora a importância da Agricultura Familiar enquanto atividade econômica, notadamente em um estado marcado historicamente pela presença do latifúndio e que por diversas razões, dentre elas as condições desfavoráveis pelas quais a agricultura familiar passou e ainda passa, perde mais jovens para as cidades a cada dia que passa, por uma série de fatores ${ }^{1}$.

\begin{abstract}
Entre 2000 e 2010, a população de 254 municípios gaúchos encolheu - o que corresponde a $51,2 \%$ do total de cidades (...) Os dados divulgados pelo IBGE são definitivos em relação à população apurada no Censo de 2010 e confirmam a tendência de retração em pequenos municípios (...) onde pequenas cidades rurais, com menos de 10 mil habitantes, perderam parte significativa de seus moradores (...) É a migração dos jovens em busca de trabalho para os centros regionais que levaria ao encolhimento populacional (AMORIM, 2011).
\end{abstract}

Uma nova compreensão de Escola do Campo torna-se uma alternativa tanto para o jovem do meio rural, quanto para sua família. Na medida em que o êxodo rural se intensifica, mais as propriedades ficam comprometidas com a sucessão familiar a curto prazo, visto que muitos adolescentes saem do campo para cursar o ensino médio, o que se dá em torno dos seus 13 ou 14 anos. Daí resulta a importância das EFAs na formação destes jovens, permitindo a organicidade da Pedagogia da Alternância por meio de seus instrumentos pedagógicos, que possibilita ao jovem a opção de permanecer no Campo. Sem a qualificação e acesso à educação de qualidade, contextualizada e problematizadora dessa realidade, seguirá a reprodução da reportagem acima, em outras palavras, cada vez mais os jovens deixarão o

\footnotetext{
1 Sobre a temática da saída dos jovens do Campo brasileiro, uma série de trabalhos vem sendo produzidos no Brasil, dada a importância desse tema, justamente porque trata-se aqui, de discutir sobre a existência da/s próxima/as geração/ões de Agricultores/as Familiares do país. Ver: CASTRO, Elisa Guaraná...(et al.) Os jovens estão indo embora?: Juventude rural e a construção de um ator político. Rio de Janeiro:Mauad X; Seropédica, RJ: EDUR, 2009
}

Campo, comprometendo assim a sucessão das propriedades familiares.

Figura 1 - Estrutura de organização das EFAs AIMFR - UNEFAB - AGEFA

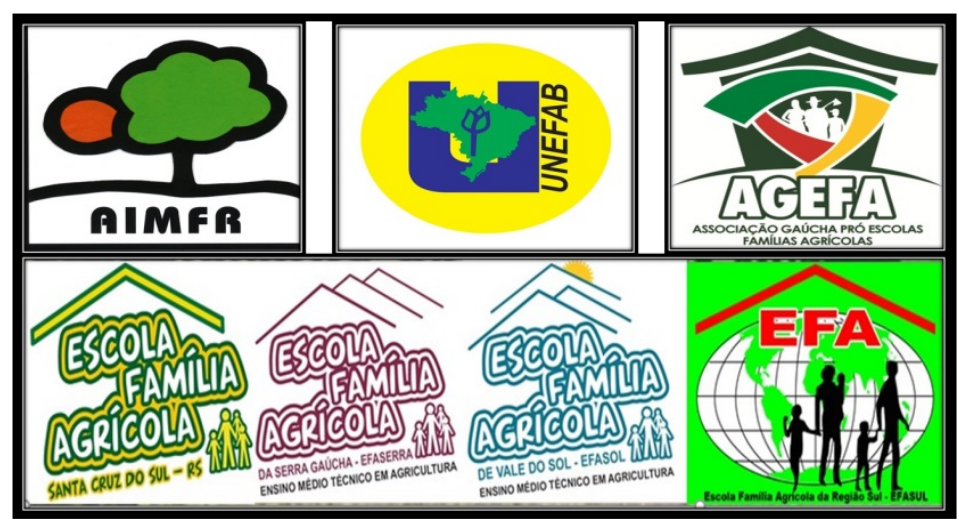

Fonte: Elaborada pelos autores.

É na ampliação desse debate e na oferta de outras possibilidades aos jovens do Campo, através da educação, que as EFAs vêm se debruçando nesses últimos anos no RS, mesmo com todas as dificuldades encontradas. Não obstante, a AGEFA vai articular desde a sua fundação a criação de até o momento mais três EFA's - EFASERRA - Escola Família Agrícola da Serra Gaúcha (2013), com sede em Caxias do Sul, na região serrana do estado. A EFASOL - Escola Família Agrícola de Vale do Sol (2014), sediada em Vale do Sol, no Vale do Rio Pardo, atendendo também estudantes do Centro Serra, do RS. E por fim, a EFASUL - Escola Família Agrícola da Região Sul (2016), sediada em Canguçu, sul do RS. Desta forma, em 2016, já são quatro EFA's no Rio Grande do Sul, trabalhando com Ensino Médio e Técnico em Agricultura, somando 245 estudantes na formação $\left(1^{\circ}, 2^{\circ}\right.$ e $3^{\circ}$ ano), 164 egressos. Portanto, já chegando a mais de 400 estudantes e famílias envolvidas, nesses 7 anos de articulação das EFAs, oriundos de cerca de 30 municípios do estado, num total de cerca de 200 comunidades do Campo gaúcho. 


\section{A Pedagogia da Alternância e o ensino da História na EFASC}

Muitos pesquisadores debruçam-se sobre as temáticas que envolvem o camponês/agricultor familiar, criando campos ideológicos diversos, que consideram a posse e o uso da terra como propriedade, a utilização da mão-de-obra na produção, o acesso a tecnologias e sistemas integrados de produção, entre outros. No mesmo sentido é o debate travado na área da educação, ocasião em que são estabelecidas duas linhas de educação oferecidas ao público rural/do Campo, expressas na classificação de educação rural/do Campo. Em muitas ocasiões, pontuando objetivamente essas duas compreensões, afirmando que "enquanto a Educação Rural é um projeto externo ao campesinato, a Educação do Campo nasce das experiências camponesas de resistência em seus territórios" (FERNANDES, 2009, p. 50).

\begin{abstract}
$\mathrm{Na}$ trajetória da educação rural, o homem do campo foi concebido como exemplo do atraso, e a política educacional se organizava em conformidade com os interesses capitalistas predominantes em cada conjuntura (...) Excetuando as experiências desenvolvidas por Paulo Freire, as Escolas Família Agrícolas (EFAs) que chegaram ao Brasil na década de 1960 e as experiências das Casas Familiares Rurais (CFRs), que ocorreram em Alagoas e Pernambuco, tendo se estendido para a região Sul do Brasil, entre 1989 e 1990, a história da educação brasileira mostra o predomínio de uma educação que objetivava "treinar e educar" os sujeitos "rústicos" do rural. As EFAs e as CFRs têm como sujeitos centrais os filhos dos pequenos produtores $\mathrm{e}$ utilizam-se da Pedagogia da Alternância, caracterizada por um projeto pedagógico que reúne atividades escolares e outras planejadas para desenvolvimento na propriedade de origem do aluno (SOUZA, 2008).
\end{abstract}

Partindo do pressuposto de que os jovens do campo não necessitam ser capacitados, muito menos treinados, e sim ter acesso à educação de qualidade, a EFASC, através da Pedagogia da Alternância apresenta-se como uma perspectiva educacional alternativa a essa lógica de escola técnica, e inovadora para os adolescentes que residem no Vale do Rio Pardo do RS. Mais do que isso, apresenta-se como uma escola contextualizada ao meio no qual os jovens estão inseridos. Justamente porque "[...] a permanência do jovem estudante da EFASC no meio rural não é uma obrigação, mas sim uma consequência dos anos de formação que este construiu junto à escola, articulado com os interesses de sua família e do meio social como num todo" (POZZEBON, 2015, p. 29).

A proposta educacional da Pedagogia da Alternância está imbricada desde a sua origem na vinculação entre os saberes institucionais e científicos e os saberes populares e/ou de senso comum. O pai e agricultor, que na década de 30 na França, percebe que seu filho de 13 anos não demonstra interesse pela escola por esta estar alienada e distante do contexto rural daquela comunidade, entende que seu filho precisa aprender de outro modo. Ou seja, percebe que a aprendizagem ofertada pela escola tradicional considera o conhecimento e a própria ação de aprender como um processo linear, num contexto desconexo no qual se valida apenas a simples transmissão, reprodução e aquisição de conhecimento (VERGÜTZ, 2013, p. 92).

Os desafios educacionais são muitos e a partir da uma realidade complexa também é necessário um pensamento a partir de múltiplas dimensões, capaz de entender a complexidade verdadeira e produzir um conhecimento que leve em conta essa mesma amplitude. (MORAES, 1997). A EFASC procura dar conta da realidade complexa do campo e construir uma educação diferenciada a partir desta realidade dos sujeitos que a compõem. Pois "quanto mais assumam os homens uma postura ativa na investigação de sua temática, tanto mais aprofundam a sua tomada de consciência em torno da realidade e, explicitando sua temática significativa, se apropriam dela" (FREIRE, 1987, p. 98-99). Daí a relevância e protagonismo que deve ter o ensino de História, na EFASC, pois trata-se de um público historicamente desassistido pela educação, os agricultores/as familiares.

A produção acadêmica e as publicações sobre ensino de História se ampliaram, assim como muitas problematizações relevantes sobre Ensino e História, por diferentes agentes e instituições, procurando responder a questões emergentes nesse campo de 
análise. Objetivamos, nos limites deste espaço textual, refletir criticamente sobre o lugar, o papel, os objetivos e a importância da História na educação básica, mais especificamente, no ensino fundamental. $\mathrm{Na}$ construção da análise, trataremos de novos e velhos temas, percursos e documentos, sugestões curriculares e produções textuais, frutos de políticas públicas, movimentos sociais e experiências de ensino e pesquisa. (SILVA e FONSECA, 2010, p.02).

Para tanto, o ensino da História na escola se dá numa perspectiva interdisciplinar, numa área do conhecimento denominada Ciências Humanas e Sociais. Contrária à formação tradicional cartesiana $^{2}$, o que importa em um desafio ainda maior, porquanto persiste na educação uma fragmentação da ciência, o que fez com que o diálogo entre as diferentes disciplinas desapareça, não levando em conta os múltiplos saberes que a ciência permite relacionar. Embora, seja de fundamental importância, a compreensão por parte do do/a professor/a, de que o trabalho por área do conhecimento ou interdisciplinar, não anule ou empobreça a História enquanto ciência, com suas prerrogativas e especificidades, caindo numa "cilada", de tratar a História numa perspectiva presentista, sem compromisso com a interpretação do saber histórico.

\begin{abstract}
Ao mesmo tempo em que essa configuração abre grandes avenidas para a interlocução e ações conjuntas com outras disciplinas, estabelece-se o risco do presentismo e o utilitarismo para as Ciências Humanas no currículo, com o que a História perde a sua especificidade e as Humanidades perdem a sua profundidade e capacidade de contribuir efetivamente e criticamente para a formação do jovem, conformando-se à mera instrução, talvez mesmo o adestramento para o mercado de trabalho e de consumo. (CERRI, 2013, p.10).
\end{abstract}

Repensar a História enquanto disciplina escolar exige dos profissionais, reflexões que envolvem percepções que vão além de conteúdo, de

\footnotetext{
${ }^{2}$ O paradigma cartesiano-newtoniamo destaca-se pela busca constante da certeza através de ordenações mecânicas segmentadas pela separação sucessiva obedecendo sempre à razão. É preciso separar para conhecer as partes e depois conhecer o todo. Um processo mecânico para respostas absolutas e verdadeiras sobre o conhecimento - ordem, separabilidade e razão.
}

métodos de ensino ou recursos didáticos. Importa pensar o ensino da História enquanto exercício fundamental, para a formação de pessoas que tenham a capacidade de análise para além do senso comum, dando assim, razão dos seus sentidos político, social e cultural.

Contrariamente a esta perspectiva, a EFASC, através de seus instrumentos pedagógicos que materializam a Pedagogia da Alternância, relaciona os saberes, os que são produzidos na propriedade, na família e na comunidade na qual o jovem está inserido, com os saberes produzidos na escola, a partir de uma perspectiva freireana que assevera que "Não há saber mais, nem saber menos, há saberes diferentes" (FREIRE, 1987, p. 68). Ou seja, é importante colocar os saberes no mesmo patamar, visando não hierarquizá-los e nem estabelecer graus de importância no processo educativo. Portanto, o saber produzido pelos/as Agricultores/as Familiares, somado ao saber produzido na EFASC por meio dos monitores/professores tem a a mesma importância na formação dos estudantes, pois trata-se de não desvincular o saber popular, do saber científico. Assim, a Pedagogia da Alternância pode se apresentar numa perspectiva de educação problematizadora e crítica da realidade, contribuindo para uma educação que propõe e pressupõe uma "Ecologia de Saberes", como aponta Boaventura Sousa Santos.

\begin{abstract}
A ecologia de saberes expande o carácter testemunhal dos conhecimentos de forma a abarcar igualmente as relações entre o conhecimento científico e não-científico, alargando deste modo o alcance da intersubjectividade como interconhecimento e vice-versa. (...). Muitas das experiências subalternas de resistência são locais ou foram localizadas e assim tornadas irrelevantes ou inexistentes pelo conhecimento abissal moderno, o único capaz de gerar experiências globais (SANTOS, 2015, p. 30).
\end{abstract}

Sobre a interdisciplinaridade, Thiesen (2008, p. 02) apresenta-a "como um movimento contemporâneo que emerge na perspectiva da dialogicidade e da integração das ciências e do conhecimento, vem buscando romper com o caráter de hiperespecialização e com a fragmentação dos 
saberes". É um ir além da integração das disciplinas, relacionando conteúdos e envolvendo os sujeitos no processo através da partilha caminhando na perspectiva de uma Educação do Campo que respeite os sujeitos do Campo e todas as relações sociais e produtivas existentes no contexto da agricultura familiar. Assim, na área de Ciências Humanas e Sociais, a História se apresenta como um "fio condutor" que inclui e dialoga com outras perspectivas de análises da realidade dos estudantes da EFASC, bem como da sociedade como num todo.

Neste sentido esse processo pedagógico na EFASC aponta para a não separação da realidade empírica da científica, mas sim entender que a experiência, a sabedoria, o cotidiano são produtos e efeitos daquilo que produz. É a compreensão de que na experiência o sujeito produz a sociedade e é por ela mesma produzido tanto em questões científicas como culturais e sociais, isto é, o sujeito, sua experiência, seu conhecimento é parte daquilo que observa, vive, cria e transforma. Essa abordagem complexa se coaduna com a Pedagogia da Alternância reconhecendo e aceitando a incerteza, o contraditório e não contraditório numa lógica ternária e não binária, dicotomizada, pois reconhece a multidimensionalidade do sujeito e as multirreferencialidades possíveis nas relações (SOMMERMANN, 2006; NICOLESCU, 1999; CREMA, 1993).

Assim, a História, dialogando com as demais disciplinas ${ }^{3}$ na área de Ciências Humanas e Sociais, passa a desempenhar um papel de protagonismo na formação dos estudantes, fazendo a ligação do que os estudantes trazem da sua realidade. Portanto, "o pensar interdisciplinar parte do princípio de que nenhuma forma de conhecimento é em si mesma

\footnotetext{
3 A prática curricular da EFASC está reorganizada considerando as proximidades entre os conteúdos das diferentes disciplinas do Ensino Médio e Técnico em Agricultura e as temáticas do Plano de Formação. O currículo está formado em seis grandes áreas do conhecimento: Produção Agropecuária, Engenharias, Ciências Humanas e Sociais, Linguagem e Gestão e Projetos. A área de Ciências Humanas e Sociais abrange as seguintes disciplinas do Ensino Médio e Ensino Técnico em Agricultura, segundo o Plano de Curso da escola: História, Geografia, Filosofia, Sociologia, Ensino Religioso, Direito e Cidadania.
}

racional. Tenta, pois, o diálogo com outras formas de conhecimento, deixando -se interpenetrar por elas. (...) não se ensina, nem se aprende, vive-se, exercese". (FAZENDA, 2001, p. 17).

Isso coloca na História um protagonismo dentro da área do conhecimento, no sentido de amparar historicamente, com seus fundamentos, a discussão que se quer empreender na aula, portanto, podendo garantir a contextualização da discussão na perspectiva da historicidade, reduzindo muito o risco de cair num reducionismo analítico. O deslocamento história/historicidade marca uma diferença entre as concepções de história, de um lado como conteúdo, e de outro como efeito de sentido (...) Trabalhar a historicidade implica em observar os processos de constituição dos sentidos e com isso desconstruir as ilusões de clareza e de certitude. (NUNES, 2005, p.01)

Nesse caso, o Ensino da História, na área de Ciências Humanas e Sociais, na perspectiva educativa da Pedagogia da Alternância, permite a contribuição da ciência histórica, entrelaçando os instrumentos pedagógicos, fazendo com que esses, construídos historicamente pelos sujeitos do Campo, cumpram seu papel frente aos saberes aos quais estão propostos, pois os estudantes ao desenvolver os instrumentos, estarão em contato direto com suas famílias e comunidades, historicizando e organizando as informações que chegarão para as aulas, orientando as demais áreas do conhecimento da EFASC. A figura 2 apresenta os instrumentos da Pedagogia da Alternância: 
Figura 2 - Pedagogia da Alternância e instrumentos pedagógicos

\begin{tabular}{|c|c|}
\hline A Pedagogia da Alter & ância e seus Instrumentos Pedagógicos \\
\hline Classificação & Instrumentos Pedagógicos - Atividades \\
\hline & * Plano de Estudo (PE) \\
\hline Instrumentos e atividades de & * Folha de Observação (FO) \\
\hline Pesquisa & * Caderno da Realidade \\
\hline & - Estágios \\
\hline & * Colocação em Comum (CC) \\
\hline Instrumentos e atividades de comunicação/relação & * Tutoria \\
\hline & ${ }^{*}$ Caderno de Acompanhamento da Alternância (CA) \\
\hline & * Visita à família e à comunidade \\
\hline & * Estágio de Vivência \\
\hline & * Envio \\
\hline & * Visita e Viagem de Estudo \\
\hline & * Serão de Estudo \\
\hline Instrumentos didáticos - pedagógicos & * Intervenção Externa \\
\hline & * Cadernos didáticos para as aulas/cursos \\
\hline & * Atividade de Retorno/Experiências \\
\hline & * Projeto Profissional do Jovem (PPJ) \\
\hline Instrumentos de avaliação & * Formativa / Continuada \\
\hline
\end{tabular}

Fonte: Adaptada dos autores e também de: FONSÊCA e MEDEIROS, 2006, p. 113. DE BURGHGRAVE, 2011, $149-150$.

O ensino da História na EFASC, na perspectiva educativa da Pedagogia da Alternância, conta com uma gama de instrumentos pedagógicos construídos ao longo dos tempos, sempre em discussão e (re)significação. Como aponta a figura abaixo, demonstrando o quanto que para efetivar uma Alternância, que não se limite apenas a alternar tempos e espaços educativos, que seja uma Pedagogia da Alternância de fato, há muitos instrumentos que "tecem" esse "alternar", daí a dimensão educativa da família e comunidade nesse fazer pedagógico.

Nesse caso, destacamos especialmente três instrumentos pedagógicos que estão imbricados com o ensino de História, na EFASC. São eles: Plano de Formação, Plano de Estudos e Colocação em Comum. Esse recorte se dá por estarem nesses o fundamento do ensino da História, na EFASC.

A finalidade dos instrumentos pedagógicos dentro da metodologia da Pedagogia da
Alternância apresenta-se como uma estrutura de trabalho que possibilita a formação integral dos jovens no movimento da alternância, articulando os tempos e espaços distintos, registrando as trilhas e caminhos da alternância, como também orientando os formadores e co-formadores. É através dos instrumentos pedagógicos que é possível perceber que a Pedagogia da Alternância fundamenta-se na cooperação e na partilha do poder educativo (...). Os instrumentos pedagógicos além de assumirem a característica de registros das alternâncias se estruturam potencializando a pesquisa, a interrogação, o diálogo, a experimentação, a troca, a expressão, a sistematização através de relações com o viver, com o trabalho, com o distanciamento e com respeito aos diferentes saberes e relações existentes na humanidade (VEGÜTZ, 2013, p. 94).

O Plano de Formação é responsável por ser o "guarda-chuva" do processo de ensino da EFA, pois prevê o objetivo geral do trabalho com a turma, os temas geradores a serem desenvolvidos, as temáticas a serem pesquisadas pelos estudantes e os conteúdos a serem trabalhados A partir das temáticas estabelece-se o Plano de Estudos, uma pesquisa 
investigativa da realidade dos estudantes, que será desenvolvido durante a sessão familiar, onde a referência de estudo passa ser a família e o entorno dos estudantes. No retorno do estudante para a escola, acontece então a Colocação em Comum, que é a socialização grupal da pesquisa, dando a dimensão do que vai ser trabalhado nas aulas durante a sessão escolar. Nesse momento, podem reafirmar conteúdos pré-determinados no Plano de Formação ou sugerir novos, a serem trabalhados nas aulas.

\begin{abstract}
O instrumento pedagógico que representa a organização de todos os demais instrumentos na Pedagogia da Alternância é o Plano de Formação. A estrutura organizacional do Plano de Formação é um quadro que apresenta e organiza as sessões escolares e familiares. Desta forma oferece a possibilidade de gestão das ações pedagógicas que serão desenvolvidas durante cada sessão escolar como as temáticas dos Planos de Estudos, isto é, temáticas das pesquisas que serão desenvolvidas na família e/ou no meio sócio-profissional. Além disso, apresenta os enfoques das temáticas, as observações sobre a colocação comum, o planejamento de visitas ou viagens de estudos, a participação de colaboradores externos a fim de possibilitar aprofundar as temáticas desenvolvidas além, das competências e habilidades que serão desenvolvidas nas áreas dos conhecimentos compostas pelas disciplinas. O Plano de Formação possibilita a organização do processo educativo na Pedagogia da Alternância através da percepção do contexto de vida dos estudantes. Todo o planejamento tem origem na vida do estudante, no seu contexto familiar, social, cultural, histórico e econômico como também em suas perspectivas de futuro (VERGÜTZ, 2013, p. 99).
\end{abstract}

A seguir, a figura 3 demonstra como organizam-se os instrumentos pedagógicos estudados no presente artigo, lembrando que estes não são taxativos e que os instrumentos estão em constante elaboração e reavaliação.
Figura 3 - Pedagogia da Alternância: Plano de Formação, de Estudos e Colocação em Comum

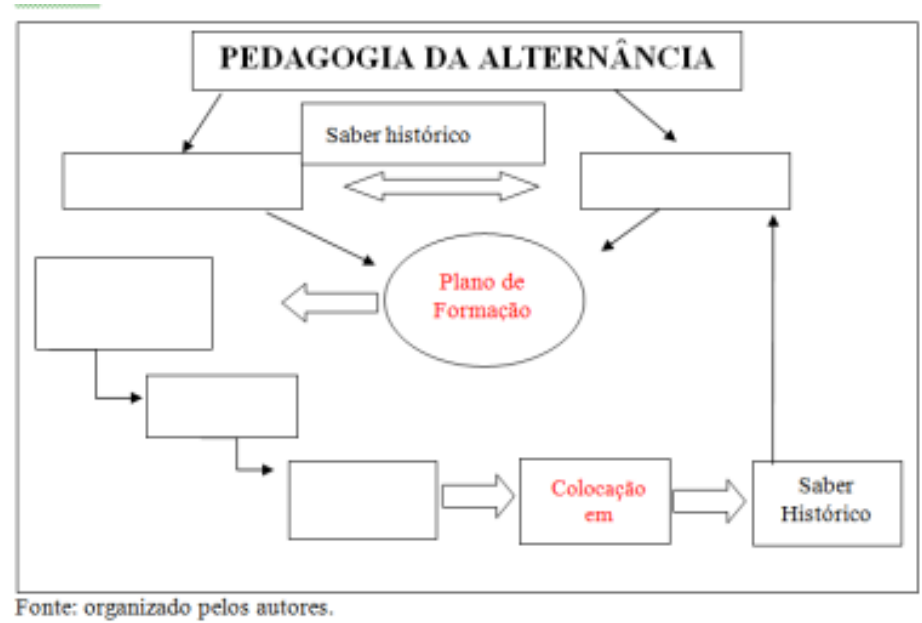

A prática da Pedagogia da Alternância envolve diversos desafios, os quais não são únicos da área de História, mas sim compartilhados por todas as áreas. Mas é importante destacar que historicamente, a História foi fortemente influenciada e instrumento consolidação de uma visão etapista e linear do processo histórico, onde ao professor cabia "ensinar" somente o conteúdo estabelecidos pelas diretrizes educacionais, num arranjo de causas efeitos e consequências dos fatos. Assim, articulada numa área do conhecimento, pressupondo a uma interdisciplinaridade, a História passa a ser uma possibilidade de interpretação da realidade, pelos próprios sujeitos dela e assim ser muito instigante, pois desafia o estudante a ser um pesquisador desde sempre, contando com a mediação e problematização do professor, trazendo inúmeros debates a cada pesquisa trazida pelo Plano de Estudos. Trata-se de uma historicização da realidade, constante.

Com o advento da Escola dos Annales, principalmente a partir do pensamento renovador de Marc Bloch no qual enfatiza que a História não deveria ser atrelada aos grandes fatos históricos, ao herói, aos grandes acontecimentos, a datação, ao dogma da verdade, etc. Na contramão disso tudo o pensador requer e defende uma ciência histórica que nos leve a compreensão do fato histórico e não a sua mera reprodução, a uma histórica crítica e reflexiva da nossa realidade sócio-cultural (COSTA, 2012, p. 1). 
Justo porque, a Pedagogia da Alternância não vê no professor o único responsável por "ensinar", mas sim uma parte do todo e nem a escola como a única possibilidade educativa dos jovens. Os pais possuem conhecimentos que são ensinados aos estudantes, os próprios jovens detém vivências diferentes que enriquecem o processo educativo quando compartilhadas. E assim, têm-se a relação com outra máxima freireana, a da superação da "educação depositária", na qual há uma imposição do conhecimento por parte do professor sobre o aluno (FREIRE, 1987).

\begin{abstract}
(...) Assim a Pedagogia da Alternância busca na sua organização alternada possibilitar aos sujeitos refletirem sobre as ações implicando numa atitude transformadora e consciente no mundo que os rodeia. (...) É a práxis do movimento de estar uma semana na sessão familiar, em casa junto à família e após estar uma semana na sessão escolar, na escola junto aos colegas e monitores. O aprender se dá no movimento da ação e da reflexão, que faz interagir diferentes saberes e experiências através da alternância marcada pelo distanciamento e consequente aproximação dos objetos cognoscíveis proporcionando o conhecer crítico e a conscientização (VERGÜTZ, 2013, p. 95)
\end{abstract}

Note-se que a Pedagogia da Alternância considera o movimento de ação e de reflexão (VERGÜTZ, 2013). Essa concepção possui reflexos imediatos no processo educativo. Tradicionalmente, a realidade do estudante é submetida ao conteúdo, ou seja, o professor possui conhecimento e o "ensina" ao estudante, o qual deve apreendê-lo e relacioná-lo, ou não, com a realidade, com a vida. Numa perspectiva vanguardista, a Pedagogia da Alternância, por meio dos seus instrumentos pedagógicos, submete 0 conteúdo à realidade do educando. Note-se que existe uma relação dialética que permeia todo o processo educativo da Pedagogia da Alternância, pois a todo momento são produzidas teses, antíteses e sínteses. Ou seja, a perspectiva da abordagem histórica se renova constantemente, trazendo ao professor/monitor e aos estudantes, bem como a suas famílias, a compreensão de que a História enquanto ciência, está sempre em construção, dialética e criticamente.
A abordagem dialética se propõe a abarcar o sistema de relações que constrói, o modo de conhecimento exterior ao sujeito, mas também as representações sociais que traduzem 0 mundo dos significados. A dialética pensa a relação da qualidade como uma das qualidades dos fatos e fenômenos, busca encontrar na parte, a compreensão e a relação com o todo; e a interioridade e a exterioridade como constitutivas dos fenômenos (MINAYO, 1994, p. 24).

Assim se pode construir um processo educativo que tenha como premissa a construção coletiva do saber histórico, dos "saberes de experiência feitos ${ }^{4 ",}$ que muitas vezes contrapõem as bases de uma ciência, dirigida pela lógica matemática das provas materiais e contraprovas, que pretensamente tentam explicar e quantificar o conhecimento/saber. $E$ é justamente nessa aproximação entre a sabedoria popular e 0 a produção cientifizada, que reside o ganho maior da humanidade, pois ambas são frutos da inventividade e da necessidade humana de superar suas necessidades básicas, portanto, irmãs do mesmo processo de criatividade e de resolução de problemas, imposto pela natureza ou pelas próprias relações humanas.

É nessa direção que o ensino da História na EFASC caminha, na contextualização dos sujeitos do Campo, tendo a História de vida do estudante, da sua família, terra, comunidade e seu entorno, relacionados com a "história dos livros", assim, territorializando e aproximando os conteúdos abordados com a sua realidade. Porque vai ser assim, "à medida que a sociedade vai se apropriando de determinado território, ela vai imprimindo suas marcas (...) mais ela vai moldando o território, visando atender suas necessidades ou interesses" (ETGES, 2001, p. 353).

\footnotetext{
4 Paulo Freire reitera essa perspectiva "saberes de experiência feitos", na obra Pedagogia da Esperança: Um reencontro com a Pedagogia do Oprimido, enfatizando a importância do saber popular, não como um saber subalterno, mas sim como um produto da vivência e experiência humana. Ver: FREIRE, Paulo. Pedagogia da Esperança: Um reencontro com a Pedagogia do Oprimido. Rio de Janeiro: Paz e Terra, 1992.
} 
Possibilitando entender assim as relações sócio-culturais que constituem os sujeitos, viventes nesses territórios, tornando o saber histórico útil e constitutivo de sua vida. Busca-se o diálogo e a construção de uma educação que atenda às necessidades dos agricultores familiares e seus filhos, passando pelo olhar historiográfico. É a materialização de uma Pedagogia da Alternância voltada à formação humana, social, ética e política e, portanto, semeando possibilidades emancipatórias, tendo força na coletividade e na luta por uma possível transformação radical das condições de vida da humanidade.

\section{Considerações finais}

A relevância do conhecimento científico é, sem dúvidas, a busca de conhecimentos, tanto em seu significado estrito, como na criação de novos conhecimentos à luz do acervo cultural estabelecido pela tradição, que precisa inexoravelmente dialogar com o saber popular, aquele forjado longe da academia, mas que povoa o viver das pessoas, suas práticas sociais, porque é nesse contexto que "quanto mais assumam os homens uma postura ativa na investigação de sua temática, tanto mais aprofundam a sua tomada de consciência em torno da realidade e, explicitando sua temática significativa, se apropriam dela" (FREIRE, 1978, p. 98-99), possibilitando assim tornarem-se sujeitos e protagonistas de sua História.

Nessa perspectiva, a escola precisa ser um espaço pronto para receber, trabalhar, com a diversidade cultural. Ela precisa estar inserida na realidade social que a permeia. É ilusão pensar que os problemas sociais ficam além muros da escola, pelo contrário, eles estão presentes no dia-a-dia das salas de aula e os professores precisam estar preparados para atuar com as diferentes realidades que envolvem o ambiente escolar.

Nesse sentido, o presente artigo teve como objetivo analisar de que forma se dá o contexto do ensino da História na EFASC, na perspectiva das Ciências Humanas e Sociais, a partir da Pedagogia da Alternância, uma alternativa e uma oportunidade de educação aos povos do Campo, preteridos historicamente do acesso a políticas públicas, especialmente da Educação.

Nesse caso, a dinâmica da Pedagogia da Alternância, com os seus instrumentos que se trouxe para o debate nesse trabalho: O Plano de Formação, o Plano de Estudos e a Colocação em Comum, dão a dimensão do quanto o debate vinculado ao ensino de História na EFASC, se constitui num fazer histórico constante, no qual os sujeitos da pesquisa estão diretamente ligados aos seus estudos, trazendo para o debate de aula, a realidade pesquisada, a partir dos saberes que esses estudantes encontrarão fora do ambiente escolar. Possibilitando, após a interpretação dialogada na aula de Ciências Humanas e Sociais, que esses estudantes possam retornar aos sujeitos pesquisados e articular novas interpretações acerca do estudo feito, dando um caráter de uma "História viva" e em constante construção.

Destacamos que qualquer tentativa de renovação do ensino de história requer uma prática corajosa. É necessário ter coragem para superar velhas práticas, repetidas cotidianamente, para ultrapassar programas oficiais e topar novos desafios. É necessário fazer com a História enquanto ciência e disciplina escolar, nesse caso, componente da área de Ciências Humanas e Sociais, cumpra o seu papel de historicizar os processos sociais aos quais os seus/suas estudantes estão inseridos, permitindo e estimulando para que os/as mesmos, problematizem a realidade vivida, para só assim terem condições reais de tentar transformá-la.

Como sugestão para estudos futuros, menciona-se a importância de existirem novos trabalhos de pesquisa acerca do tema do presente artigo, como por exemplo, a Pedagogia da Alternância aplicada não somente às populações do Campo, mas também às populações urbanas. Isso seria possível?

Por outro lado, a escola não desempenha sua função social desconectada da sociedade. Pelo contrário, ela encontra-se inserida em um contexto, o qual é único para cada escola. Ademais, leis são criadas para garantir que a educação no Brasil seja 
de acesso universal e de qualidade. Cabe à sociedade acompanhar e fiscalizar essas legislações a fim de que sejam concretizadas e a sociedade civil ser consideradas pelos formuladores das políticas públicas e leis, como protagonistas de suas histórias.

\section{Referências}

AMORIM, F. Dados do IBEGE apontam que mais da metade das cidades gaúchas tiveram déficit populacional. Zero Hora: Porto Alegre, Edição de 03 de junho 2011. Disponivel em: $<$ http://zerohora.clicrbs.com.br/zerohora>. Acesso em: 01 ago. 2016.

BEGNAMI, J. B. Uma geografia da Pedagogia da Alternância no Brasil. Documentos Pedagógicos - UNEFAB, Brasília, 2004.

COSTA, Alex Silva. A importância do ensino de História nas escolas e suas implicações na vida social. Revista Anagrama: Revista Científica Interdisciplinar da Graduação. Ano 5 - Edição 2 Dezembro de 2011 - Fevereiro de 2012. p.01. anagrama@usp.br. Disponível em: http://www.revistas.univerciencia.org/index.php/a nagrama/article/viewFile/7544/7012. Acessado em 10/08/2016.

COSTA, J. P. R. Escola família agrícola de Santa Cruz do Sul - EFASC: uma contribuição ao desenvolvimento da região do Vale do Rio Pardo a partir da pedagogia da alternância. 2012. 226f. Dissertaçã (Mestrado em Desenvolvimento Regional) - Universidade de Santa Cruz do Sul, Santa Cruz do Sul, 2012. Disponivel em: $<$ http://repositorio.unisc.br/jspui/handle/11624/42 2>. Acesso em: 12 jul. 2016.

CREMA, Roberto. Além das disciplinas: reflexões sobre a transdiscipinaridade geral". In: WEIL, Pierre, D'AMBROSIO, Ubiratan. Rumo à nova transdisciplinaridade: sistemas abertos de conhecimento. São Paulo: Summus Editorial, 1993.

DE BURGHGRAVE. Thierry. Vagabundos, não senhor Cidadãos brasileiros e planetários: uma experiência educativa pioneira do Campo. Orizona / GO: UNEFAB, 2011.

ETGES, Virgínia Elisabeta. A região no contexto da globalização: O caso do Vale do Rio Pardo. IN: VOGT, Olgário Paulo. SILVEIRA, Rogério Leandro Lima da (orgs). Vele do Rio Pardo: (re) conhecendo a região. Santa Cruz do Sul: EDUNISC. 2001, p. 353.

FAZENDA, I. Práticas interdisciplinares na escola. São Paulo: Cortez, 2001
FERNANDES, B. M. Introdução à Educação do Campo: povos, territórios, saberes da terra, movimentos sociais, sustentabilidade. In: GERDA, M. S.; FOERTE, E.; CALIARI, R. Educação do campo e território. Vitória: UFES, Programa de Pós-Graduação em Educação, 2009. p. 50. Disponivel em: <http://www.ce.ufes.br/educacaodocampo/down/ educacaodocampo.pdf>. Acesso em: 01 ago. 2016.

FONSÊCA, Maria Aparecida. MEDEIROS, Maria Osnette de. Currículo em Alternância: Uma nova perspectiva para a educação do campo. IN: QUEIROZ, João Batista Pereira de. SILVA, Virgínia Costa e. PACHCO, Zuleika. (orgs). Pedagogia da Alternância - Construindo a Educação do Campo. Goiânia: Ed. da UCG; Brasília, Ed. Universa, 2006.

FREIRE, P. Ação cultural para a liberdade. 3. ed. Rio de Janeiro: Paz e Terra, 1978.

FREIRE, Paulo. Pedagogia da Esperança: Um reencontro com a Pedagogia do Oprimido. Rio de Janeiro: Paz e Terra, 1992.

FREIRE, P. Pedagogia do oprimido. 17ª ed. Rio de Janeiro: Paz e Terra, 1987.

GIMONET, J. C. Nascimento e desenvolvimnto de um movimento educativo: As casas familiares rurais de educação e de orientação. I Seminário Internacional da Pedagogia da Alternância Alternância e Desenvolvimento, Salvador, n. 2, Novembro 1999.

MARIRRODRIGA, R. G.; CALVÓ, P.. Formação em alternância e desenvolvimento local: o movimento educativo dos CEFFA no mundo. Tradução de Luiz da Silva Peixoto; João Baptista Begnami, et al. Belo Horizonte: O Lutador, 2010.

MINAYO, Maria Cecília de Souza. Ciência, Técnica e Arte: O desafio da pesquisa social. IN: MINAYO, Maria Cecília de Souza (org). DESLANDES, Suely Ferreira. NETO, Otávio Cruz, GOMES. Romeu. MINAYO, Maria Cecília de Souza. Pesquisa social: teoria, método e criatividade. Petrópolis: RJ, Vozes, 1994.

MORAES, M. C. O paradigma educacional emergente. Campinas: Papirus, 1997.

NICOLESCU, Basarab. O Manifesto da Transdisciplinaridade. São Paulo: TRIOM, 1999.

POZZEBON, Adair. A inserção socioprofissional dos jovens egressos da Escola Família Agrícola de Santa Cruz do Sul no Vale do Rio pardo, RS: Uma contribuição para o desenvolvimento rural. Dissertação de Mestrado - PGDR/UFRGS. 2015.

SANTOS, Boaventura de Sousa. Para além do Pensamento Abissal: Das linhas globais a uma 
ecologia de saberes. p.30. Disponível em: http://www.ces.uc.pt/bss/documentos/Para alem do pensamento abissal RCCS78.PDF. Acessado em: 10 ago. 2016.

SOMMERMAN, Américo. Inter ou Transdisciplinaridade?: da fragmentação disciplinar ao novo diálogo entre os saberes. São Paulo: Paulus, 2006.

SOUZA, M. A. D. Educação do campo: políticas, práticas pedagógicas e produção científica. CEDES, set./dezl 2008. Disponivel em: $<$ http://www.cedes.unicamp.br>. Acesso em: 01 ago. 2016.

TANTON, C. Alternância e parceria: Família e meio sócio-profissional. Pedagogia da Alternância Alternâcia e Desenvolvimento. I Seminário Internacional, Salvador, p. 98-99, 1999.

THIESEN, J. D. S. A interdisciplinaridade como um movimento articulador no processo ensinoaprendizagem. Revista Brasileira de Educação, Rio de Janeiro, 13, set./dez/ 2008. Disponivel em: $\quad<$ http://dx.doi.org/10.1590/S141324782008000300010>. Acesso em: 01 ago. 2016.

VERGÜTZ, C. L. B. Aprendizagens na Pedagogia da Alternância da Escola Família Agrícola de Santa Cruz do Sul. 2013. 174f. Dissertação (Mestrado em Educação) - Universidade de Santa Cruz do Sul, Santa Cruz do Sul, 2013. Disponivel em:

<http://repositorio.unisc.br/jspui/handle/11624/506>. Acesso em: 01 ago. 2016.
CERRI, Luis Fernando. Fronteiras interdisciplinares no ensino da história. 2013. .Disponível em: $<$ ojs.fe.unicamp.br/ged/FEH/article/download/54 62/4368 >. Acesso em: 30 nov. 2016.

NUNES, José Horta. Leitura de arquivo: historicidade e compreensão. In: Seminário de estudos em análise do discurso, 1, 2005, Porto Alegre. Anais eletrônicos... Porto Alegre: UFRGS, 2005. Disponível em: <http://www.discurso.ufrgs.br/sead2/doc/interpret acao/Jose_horta.pdf>. Acesso em: 20 out. 2016.

SILVA, Marcos Antônio da. FONSECA, Selva Guimarães. Dossiê: História, Educação $\mathrm{E}$ Interdisciplinaridade - Ensino de História hoje: errâncias, conquistas e perdas. Rev. Bras. Hist. vol.30 no.60 São Paulo, 2010. p.02. Disponível em:

$<$ http://www.scielo.br/scielo.php?script=sci arttex t\&pid=S0102-01882010000200002>. Acesso em: 30 nov. 2016. 